\title{
An examination of synaptic proteins following chronic haloperidol in a rat model of tardive dyskinesia
}

\author{
Mona Kessas, Meaghan Creed, and José N. Nobrega \\ University of Toronto, Toronto, ON, Canada
}

\begin{abstract}
Tardive dyskinesia (TD) is a late-onset side effect mainly affecting the orofacial region of patients treated chronically with classic antipsychotic drugs such as haloperidol (HAL). The causes of TD remain unknown. We hypothesized that faulty synaptic re-organization might be related to TD-like syndromes and used the vacuous chewing movements (VCM) model in rats to investigate the expression of four synaptic proteins, synaptophysin, syntaxin, spinophilin and PSD-95, in brains of HAL-treated rats. Male Sprague-Dawley rats were treated for 14 weeks with either haloperidol decanoate $(21 \mathrm{mg} / \mathrm{kg}$ once every 3 weeks, I.M) or vehicle and VCMs were monitored on a weekly basis. As expected, VCMs developed reliably and were consistently more pronounced in some rats than in others. Using immunohistochemistry in anatomically preserved brain sections as well as Western Blot analyses of whole cells or synaptosomal fractions in striatal tissue, we found no significant effect of chronic HAL on levels of these proteins. Neither did we find significant differences in the levels of the four synaptic markers when comparing rats showing High vs. Low levels of VCMs. These results suggest that structural synaptic alterations (e.g. involving increased number of synapses) may not be the underlying mechanism of oral dyskinesias induced by chronic antipsychotic drug treatment. The possibility that functional neuroplastic changes occur remains to be investigated. Keywords: antipsychotic drugs, tardive dyskinesia, vacuous chewing movements, haloperidol, oral dyskinesias, synaptic plasticity.
\end{abstract}

Received 9 October 2010; received in revised form 11 December 2010; accepted 20 December 2010. Available on line 28 December 2010

\section{Introduction}

Tardive dyskinesia (TD) is a persistent latedeveloping movement disorder associated with chronic treatment with classical antipsychotic drugs (APDs) such as haloperidol. It affects mainly the orobuccal, lingual and facial muscles and is characterized by wormlike movements, protrusions, lip pouting, and chewing in the absence of any object (Marsalek, 2000; Soares \& McGrath, 1999). TD may persist for months or years after drug discontinuation and may in some cases be irreversible (Glazer, Morgenstern, Schooler, Berkman, $\&$ Moore, 1990). The risk of developing TD increases by approximately $5 \%$ per year of treatment and constitutes a major limitation of antipsychotic therapy (Glazer, Morgenstern, \& Doucette, 1993). Newer APDs, such

Mona Kessas, Meaghan Creed, and José N. Nobrega, Neuroimaging Research Section, Centre for Addiction and Mental Health and Departments of Pharmacology and Toxicology, University of Toronto, Toronto, Ontario, Canada. José N. Nobrega, Neuroimaging is also at Departments of Psychiatry and Psychology, University of Toronto, Toronto, Ontario, Canada. Correspondence regarding this article should be directed to: José N. Nobrega, Neuroimaging Research Section, Centre for Addiction \& Mental Health, 250 College Street, Toronto, Ontario M5T 1R8, Canada. Phone: (416) 535-8501 Ext. 6259. Fax: (416)979-4739. E-mail: jose_nobrega@camh.net as clozapine and olanzepine, are associated with much lower risk of TD (Correll \& Schenk, 2008), but carry higher risks of inducing agranulocytosis, excessive weight gain, diabetes and potentially fatal metabolic complications (Haddad \& Sharma, 2007). Thus classical antipsychotic medications are still used, and TD remains a significant clinical problem (Remington, 2007).

In rats, long-term treatment with typical APDs induces spontaneous oral movements referred to as "vacuous chewing movements" (VCMs), which are characterized by repeated purposeless mouth openings with or without tongue protrusions, which mimic a number of features of the clinical syndrome (Andreassen, Meshul, Moore, \& Jorgensen, 2001; Gunne \& Growdon, 1982; Tamminga, Dale, Goodman, Kaneda, \& Kaneda, 1990; Waddington, Cross, Gamble, \& Bourne, 1983)(see Turrone, Remington, Kapur, \& Nobrega, 2003 for review). Several hypotheses have been proposed to explain the mechanism underlying dyskinesias induced by long-term APDs but none has been conclusively verified as the ultimate underlying cause of this syndrome (Abilio et al., 2004; Seeman, 2010).

Chronic HAL administration is associated with specific morphological and synaptic changes in the brain, which are suggestive to be involved both in the therapeutic of HAL and in its delayed, persistent adverse motor effects (Benes, Paskevich, Davidson, \& Domesick, 1985a, 1985b; Konradi \& Heckers, 2001). 
Alterations in the size of axon terminals, absolute number of vesicles and the size of postsynaptic densities have been reported (Benes et al., 1985a; Kerns, Sierens, Kao, Klawans, \& Carvey, 1992; Uranova et al., 1991). It has been hypothesized that schizophrenia itself may arise from inadequate synaptic organization during development (McGlashan \& Hoffman, 2000), and that neuroplasticity induced by APDs can promote functional and anatomical reorganization of neural connections (Konradi \& Heckers, 2001). In this framework TD might result from faulty re-wiring induced by chronic APD treatment.

The current study sought to address this hypothesis by quantifying levels of specific pre- and post-synaptic protein markers in HAL-treated rats showing different levels of VCMs. Synaptophysin and syntaxin are pre-synaptic proteins that are thought to reliably reflect synaptogenesis (Calakos, Bennett, Peterson, \& Scheller, 1994; Calakos \& Scheller, 1994, 1996; Sudhof, 1995). Spinophilin and PSD-95 are postsynaptic proteins involved in the remodeling of dendrite spines (El-Husseini, Schnell, Chetkovich, Nicoll, \& Bredt, 2000; Fachinetto et al., 2007; Feng et al., 2000; Fisher \& Braun, 2000; Halpain, Hipolito, \& Saffer, 1998; Kennedy, 1997, 1998; Li et al., 2004; Matus, 2000; Yan et al., 1999). We therefore reasoned that structural synaptic alterations, and more specifically increases in synapse formation, would be accompanied by increases in levels of both pre- and post-synaptic proteins. We further hypothesized that after chronic HAL such increases would be more pronounced in rats showing high levels of VCMs than in similarly treated rats showing low levels of VCMs.

\section{Methods}

\section{Subjects}

Male Sprague-Dawley rats (Charles River, Montreal, Quebec) weighing 175-200 $\mathrm{g}$ at the start of the experiment were housed in pairs in $48 \times 26 \times 20 \mathrm{~cm}$ polycarbonate cages and maintained on a 12-hour light/dark cycle with unrestricted access to food and water.

\section{Procedure}

All behavioral testing was conducted between 10 A.M. and 2 P.M. On each test day animals were moved to the testing room and allowed to acclimatize for 30 minutes. All experimental procedures conformed to the guidelines of the Canadian Council on Animal Care and were approved by the institutional Animal Care Committee. Twenty eight rats received haloperidol decanoate $(21 \mathrm{mg} / \mathrm{kg}, \mathrm{i} . \mathrm{m}$.) once every 3 weeks for a total of 4 injections. At those injection times 8 control rats received sesame oil vehicle $(n=8)$. The decanoate formulation allows for slow drug release (approximately $1 \mathrm{mg} / \mathrm{kg} /$ day). Once a week animals were observed in a quiet room on a flat round surface $(26 \mathrm{~cm}$ diameter, $50 \mathrm{~cm}$ high) by a trained rater blind to treatment. Following 2 min adaptation the number of VCMs was counted for $2 \mathrm{~min}$. Oral movements were counted only if they appeared to be purposeless (not directed at specific objects). Discrete bursts of jaw tremors or mouth openings were counted as single VCMs.

\section{Tissue preparation and immunohistochemistry}

After 14 weeks of treatment rats animals were euthanized by decapitation and brains were rapidly removed. Half of each brain was stored at $-80^{\circ} \mathrm{C}$ for immunoblotting experiments. The other half was cut into coronal slabs, post-fixed in a $4 \%$ paraformaldehyde solution containing $0.3 \%$ glutaraldehyde and then stored at $4^{\circ} \mathrm{C}$. Thirty- micron coronal sections were then cut on a vibratome and collected in phosphate-buffered saline (PBS). The following primary antibodies were used: monoclonal mouse anti-synaptophysin (SigmaAldrich, St. Louis, MO); polyclonal rabbit anti-syntaxin (Calbiochem, San Diego, CA); polyclonal rabbit antispinophilin (Upstate Biotechnology, Burlington, ON, Canada); and monoclonal mouse anti-PSD-95 (Upstate). For synaptophysin and PSD-95 non-specific staining was blocked with $2 \%$ horse serum, whereas $2 \%$ goat serum was used for immunoreactivity to spinophilin and syntaxin. All sections were initially blocked for $2 \mathrm{hr}$ at room temperature. Tissue was then incubated overnight with the appropriate primary antibody at $4^{\circ} \mathrm{C}$. Sections were then rinsed with PBS and incubated in biotinylated secondary antibody for $2 \mathrm{hr}$ at room temperature, then rinsed with PBS, incubated for $45 \mathrm{~min}$ in Vectastain Elite $\mathrm{ABC}$ reagents (Vector Labs, Burlingame, $\mathrm{CA}$ ) and then incubated in a peroxidase substrate. Sections were then washed in PBS, mounted onto slides, and allowed to dry before coverslipping.

\section{Densitometric analyses}

MCID-M5 software (Imaging Research, St Catherine's, ON, Canada) was used to measure optical density in each region of interest (caudate-putamen, cingulate and motor cortices, shell and core of the nucleus accumbens). Illumination conditions were adjusted to ensure constant background and all readings were obtained from coded slides. Sample readings for each region were first averaged for each brain section, then for all sections, and then for all subjects in each group.

\section{Isolation of whole-tissue fractions}

The caudate putamen was dissected on a cold plate $\left(-15^{\circ} \mathrm{C}\right)$ and weighed. Each sample was then sonicated in 7 volumes of boiling 1\% SDS with $50 \mathrm{mM} \mathrm{Naf}$ and further boiled for another $10 \mathrm{~min}$. Aliquots of $5 \mu 1$ were used for protein measurements (BCA assay kit, Pierce, Rockford, IL). Samples of $20 \mu \mathrm{g}$ of protein were dissolved in sample buffer $(3 \%$ 
SDS, $62 \mathrm{mM}$ Tris $\mathrm{HCl}, 0.3 \mathrm{M} \beta$-mercaptoethanol, $5 \%$ glycerol and $0.1 \%$ bromophenol blue).

\section{Isolation of synaptosomes}

Caudate-putamen samples were homogenized in 10:1 volume of buffer (0.32M sucrose, 2mM EDTA, $2 \mathrm{mM}$ EGTA, 20mM HEPES) to weight of tissue. Samples were then centrifuged at $500 \mathrm{~g}$ for $10 \mathrm{~min}$ at $4^{\circ} \mathrm{C}$. Pellets $(\mathrm{P} 1)$ were discarded and supernatants (S1) collected and mixed with cold homogenization buffer and centrifuged at $32,000 \mathrm{~g}$ for $30 \mathrm{~min}$ at $4^{\circ} \mathrm{C}$. Supernatant (S2) was discarded and the pellets (P2) were re-suspended in cold $0.1 \mathrm{M}$ phosphate buffered saline (PBS) and centrifuged at $32,000 \mathrm{~g}$ for $30 \mathrm{~min}$ at $4^{\circ} \mathrm{C}$. Pellets were collected and dissolved in $500 \mu \mathrm{l} 0.1 \mathrm{M}$ PBS and stored in $-80^{\circ} \mathrm{C}$ until immunoblotting.

\section{Sample preparation and SDS-PAGE}

Bradford assays were performed to determine total protein concentrations. Antibody concentrations and protein amounts were previously titrated to obtain optimal and low background signal for each of the four synaptic markers. Synaptosomal or whole tissue fractions were then mixed with $1 \mathrm{X}$ and $2 \mathrm{X}$ sodium dodecyl sulfate (SDS) sample buffers (1M Tris pH 6.8, 10\% SDS, glycerol, 1\% bromophenol blue) to obtain homogenates containing $0.5 \mu \mathrm{g}$ of total protein per $15 \mu \mathrm{l}$ volume for syntaxin, and PSD-95, and $1 \mu \mathrm{g}$ total protein for synaptophysin. Samples within each behavioural group were pooled to obtain sufficient protein concentrations to detect the spinophilin antigen. Samples for syntaxin, PSD-95 and spinophilin were heated to $80^{\circ} \mathrm{C}$ for $5 \mathrm{~min}$ to denature proteins. A volume of $15 \mu \mathrm{l}$ of each sample was loaded onto precast $4-20 \%$ Tris-Glycine polyacrylamide gels (Invitrogen, Carlsbad, CA). For each protein optimal conditions were established by testing different protein concentrations ( 0.1 to $0.5 \mu \mathrm{g}$ ) and different film exposure times $(10 \mathrm{sec}, 20 \mathrm{sec}, 30 \mathrm{sec}, 1 \mathrm{~min}, 5 \mathrm{~min})$. Samples from each group were loaded onto each gel. Each sample was run in triplicates in a single gel for a total of 3 samples per gel. A heterogeneous mixture of brain tissue was included in each gel as a control to determine between-blot variability. In addition, $\beta$-tubulin was used as an internal control for all blots. A pre-stained molecular weight marker (MBI Fermentas, Burlington, ON, Canada; cat \# SM 0671; 10 to $180 \mathrm{kDa}$ ) was also included to verify that the specificity of the antibodies used. Proteins were separated by electrophoresis at $125 \mathrm{~V}$ for $2 \mathrm{hr}$ using a single power source. Gels were transferred onto Bio Trace PVDF membranes (Gelman Laboratory, Ann Arbor, MI) for $90 \mathrm{~min}$ at $400 \mathrm{~mA}$ in Trisglycine buffer containing 10\% methanol. Membranes were then blocked for $1 \mathrm{hr}$ at room temperature in a $5 \%$ milk solution diluted in $1 \mathrm{X}$ Tris buffered saline (TBS) containing $0.1 \%$ Tween-20 (TBS-T) then serially rinsed in TBS-T. Blots were incubated overnight at $4^{\circ} \mathrm{C}$ with the aappropriate antibodies. The following primary antibodies were used: synaptophysin (mouse monoclonal, Sigma, cat \#S 5768); syntaxin (rabbit polyclonal, Calbiochem, cat \#574784); spinophilin (rabbit polyclonal, Upstate, cat \# 06-852); PSD-95 (mouse monoclonal, Sigma, cat \#P-246) and $\beta$-tubulin (rabbit polyclonal, Santa Cruz Biotechnology, Santa Cruz, CA). All primary antibodies were diluted in 5\% BSA in TBS-T. Blots were rinsed $3 \mathrm{X} 4 \mathrm{~min}$ with TBS-T then incubated in the appropriate secondary antibody for $2 \mathrm{hr}$ at RT. PSD-95 and synaptophysin sections were incubated in HRP bound anti-mouse IgG. Syntaxin and spinophilin blots were incubated in HRP-bound antirabbit IgG. $\beta$-tubulin blots were incubated in HRPbound anti-rabbit IgG. All blots were then rinsed $2 \mathrm{X}$ $5 \mathrm{~min}$ and a final $15 \mathrm{~min}$ rinse and developed in ECL-plus (Amersham, Baie d'Urfe, PQ, Canada) and exposed to Kodak Bio-Max film.

\section{Blot analyses}

Scanned images were analyzed using ImageQuant 5.2 software in a Molecular Dynamics Storm 860 phosphoimager. For each sample, volume estimates were collected, corrected with respect to background and then normalized against the corresponding loading control and the heterogeneous mixture on the blot. An average of all values for each sample was calculated.

\section{Statistical analyses}

In all experiments data were analyzed using SPSS software (Chicago, IL). Analyses of variance (ANOVA) were followed, where warranted, by independent twotailed Student's $t$ tests. $\quad \mathrm{P}<0.05$ was used to define statistical significance.

\section{Results}

\section{VCM Behaviour}

As expected, chronic HAL induced reliable VCMs over the course of treatment (Figure 1A). A repeated measures ANOVA confirmed a significant main effect of HAL treatment $(F[1,22]=44.9 ; p<.001)$, a significant effect of Time $(F[13,286]=5.16 ; p<.001)$, and a significant Treatment $X$ Time interaction $(F[13,286]=4.3 ; p<.001)$. We then separated rats on the basis of VCM severity as often done in previous studies (Egan et al., 1994; Sasaki, Kennedy, \& Nobrega, 1997; Sasaki, Kennedy, \& Nobrega, 1998). Rats consistently appearing in the low or the high end of the distribution in each of the three final weeks were classified as 'High' VCM $(n=8)$ or 'Low' VCM $(n$ $=8$ ), respectively (Figure 1B). Rats in the middle 1/3 of the distribution were not considered in these analyses. As expected, a repeated measures ANOVA for the last 3 weeks of testing confirmed a significant Treatment main effect ( $p$ $<.001)$, a significant Time main effect $(p<.001)$ and a significant Treatment $\mathrm{x}$ Time interaction $(p<.001)$ (Figure 

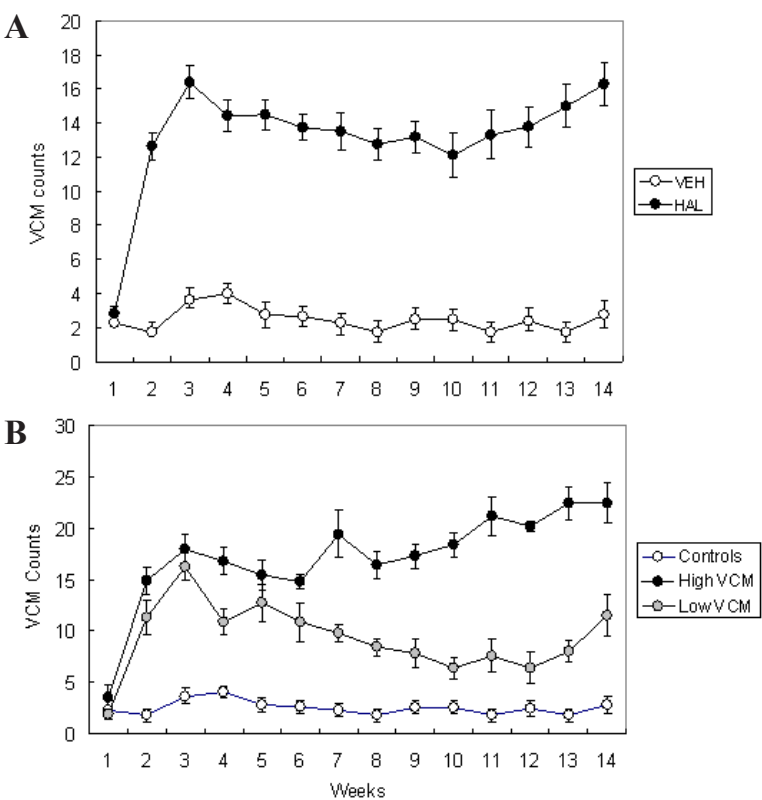

Figure 1. A). Development of VCMs in all HAL-treated $(n=28)$ and Vehicle-treated controls $(n=8)$. Values are means \pm SEM. The number of VCMs is significantly different between the two groups at all time points except for the pre-injection baseline (week 1) ( $<<0.01, \mathrm{t}$ tests). B). VCM counts in High vs. Low VCM Haloperidol-treated rats. Values are means \pm SEM. The 8 rats wit highest and the 8 rats with the lowest VCM scores during the last three weeks of treatment were labeled as High VCM or Low VCM, respectively. During the last 3 weeks there was a significant difference between High and Low VCM groups $(\mathrm{p}<0.01)$ and between Low VCM and the vehicle group (both $\mathrm{p}<0.05$ ).

1B). For the last 3 weeks of testing there was a significant difference between High and Low VCM groups $(p<.01)$ and between Low VCM and vehicle groups $(p<.05)$.

\section{Immunohistochemistry}

No significant difference between High VCM and Low VCM groups was detected for any of the four synaptic markers in any of the brain regions analyzed, including subdivisions of the caudate putamen (all $p s>.05$ ) (Figures 2 and 3). In addition, comparison of either High or Low VCM subgroups to the vehicle group failed to reveal any significance in the synaptic markers in any of the brain regions (all $p s>.05$ ). When all HAL-treated samples were compared to vehicle control samples, no significant differences in the levels of any of the synaptic markers in any of the brain regions were seen (data not shown). Plotting VCM counts against corresponding optical densities for each of the protein markers in the whole caudate-putamen also failed to reveal significant correlations for synaptophysin $(r$ $=.4 ; p>.05)$, syntaxin $(r=.4 ; p>.05)$, spinophilin $(r=.09$; $p>.5)$ or PSD-95 $(r=.2 ; p>.3)$.

\section{Immunoblotting using whole-cell fractions}

All proteins migrated with a single band at the predicted molecular weight: synaptophysin $(38 \mathrm{kDa})$,
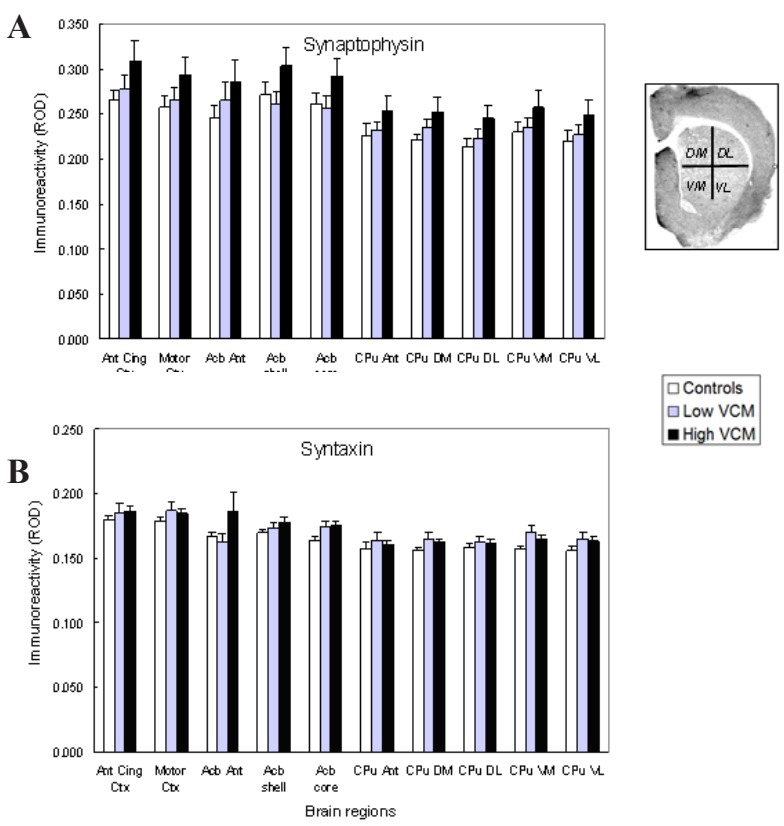

Figure 2. Brain levels of pre-synaptic proteins after chronic haloperidol. Values are means \pm SEM in relative optical density (ROD) units. $\mathrm{N}=6-8$ per group. Abbreviations: Ant Cing Ctx: Anterior cingulate cortex; Acb Ant: Anterior pole of the nucleus accumbens; Acb Shell: n. accumbens shell; Acb Core: n. accumbens core; $\mathrm{CPu}$ : caudate-putamen. The photomicrograph (spinophilin immunohistochemistry) shows the subdivisions of the $\mathrm{CPu}$ included in the analyses of all four proteins: DM: dorsomedial; DL: dorsolateral; VM: ventromedial; VL: ventrolateral. No statistically significant differences were observed in any of the brain regions examined.

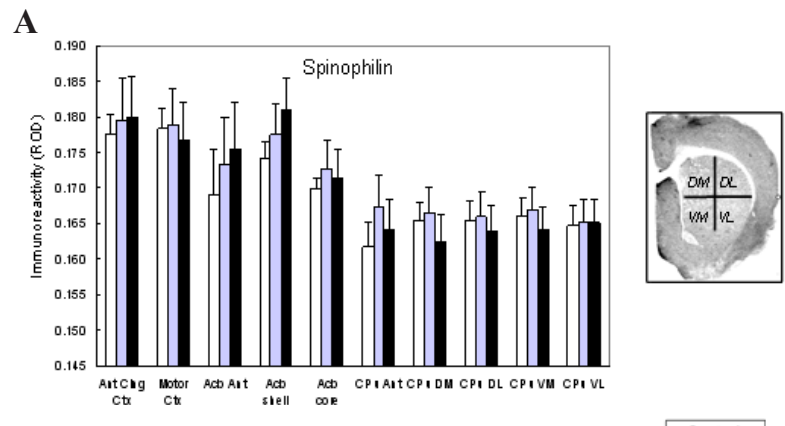

B
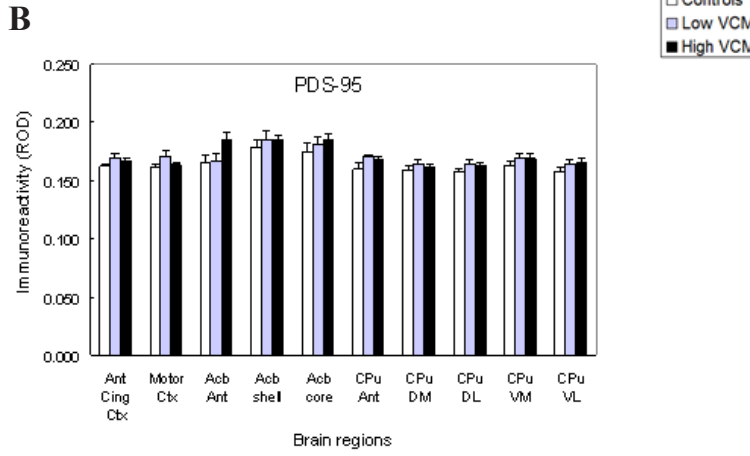

- High VCM

Figure 3. Brain regional levels of post-synaptic proteins after chronic haloperidol. Values are means \pm SEM relative optical density units (ROD). $\mathrm{N}=6-8$ pergroup. Brain region abbreviation as in Figure 2. No statistically significant differences were observed in any of the brain regions examined. 
PSD-95 (95 kDa), syntaxin (35 kDa), spinophilin (120 $\mathrm{kDa})$ and $\beta$-tubulin $(55 \mathrm{kDa})$. Typical blots for each of the synaptic markers in High VCM, Low VCM and control groups are illustrated in Figure 4. Results were normalized with $\beta$-tubulin. Analyses of variance failed to detect a significant difference between High VCM, Low VCM, and control samples in terms of synaptophysin $(\mathrm{F}[2,23]=0.81 ; \mathrm{p}>.4)$, syntaxin $(F$ $[2,23]=0.28 ; p>.5)$, spinophilin $(F[2,23]=0.61$; $p>0.5)$ or PSD-95 $(F[2,21]=1.6 ; p>.20)$ levels (Figure 5). When brain samples from all HAL-treated rats were compared to control samples, no significant differences were found in the levels of any of the proteins (all $p s>.3$; data not shown).
Immunoblotting using synaptosomal fractions

Analyses restricted to synaptosomes in caudateputamen tissues also did not indicate any differences between High VCM, Low VCM and control groups (Figure 6). ANOVAs revealed no differences for synaptophysin $(F$ $[2,23]=1.6 ; p>.2)$, syntaxin $(F[2,23]=0.11 ; p>.8)$ or PSD-95 $(F[2,22]=0.38 ; p>.6)$. Spinophilin samples had to pooled for each group prior to biochemical determinations. Group means $( \pm S E M)$ for 8 - 10 spinophilin aliquots for each group are shown in Fig. 6 but were not be subjected to statistical analyses. When samples from all HAL-treated rats were compared to the control group, ANOVAS again failed to detect a significant difference in the levels of these proteins (all $p s>.05$; data not shown).
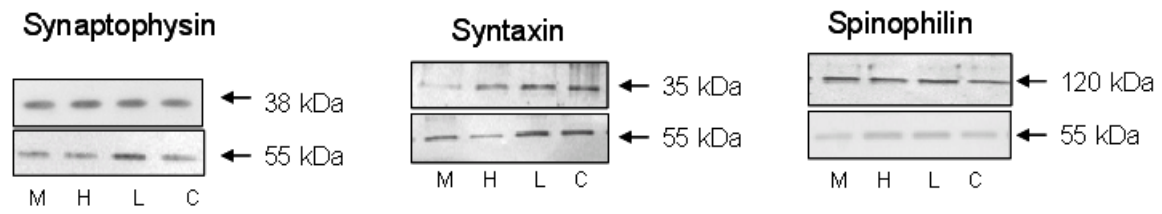

PSD-95

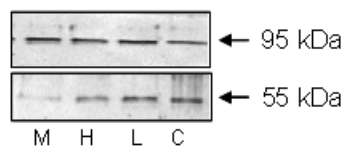

Figure 4. Representative illustrations of immunoblots for each of the four synaptic proteins. M: Heterogenous mixture used for normalization; H: High VCM; L: Low VCM: C: controls. The $55 \mathrm{kDa}$ blots are $\beta$-tubulin loading controls.

A

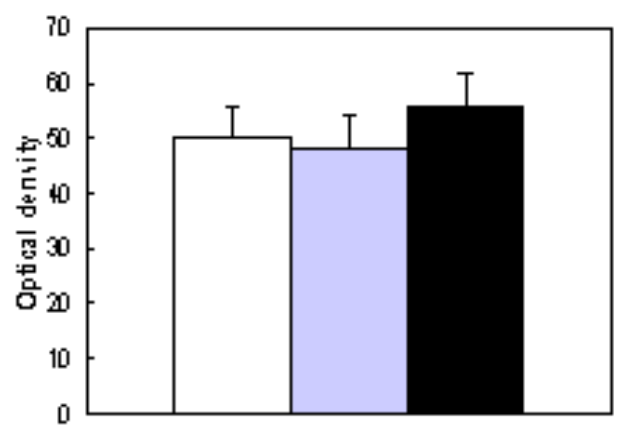

C

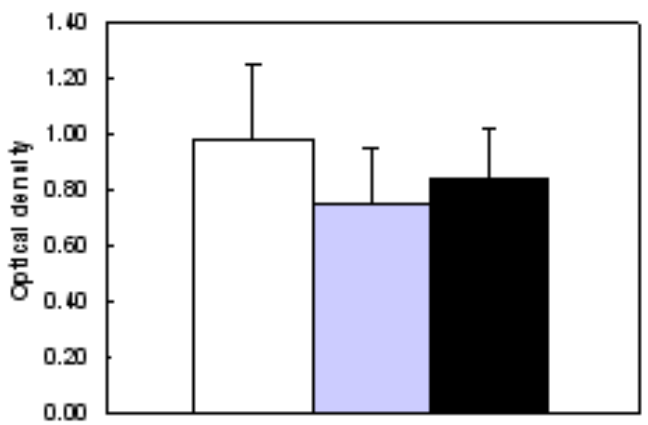

B

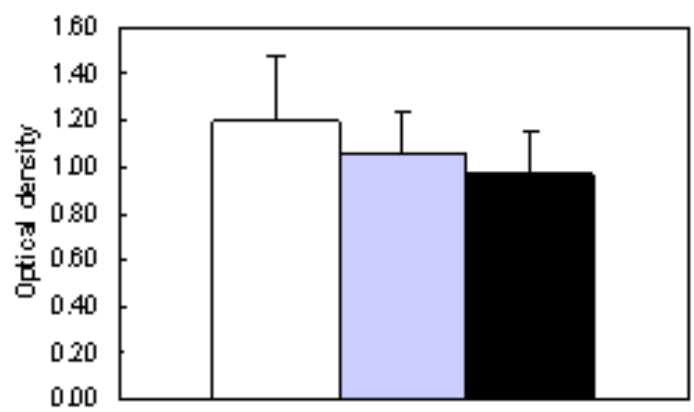

D
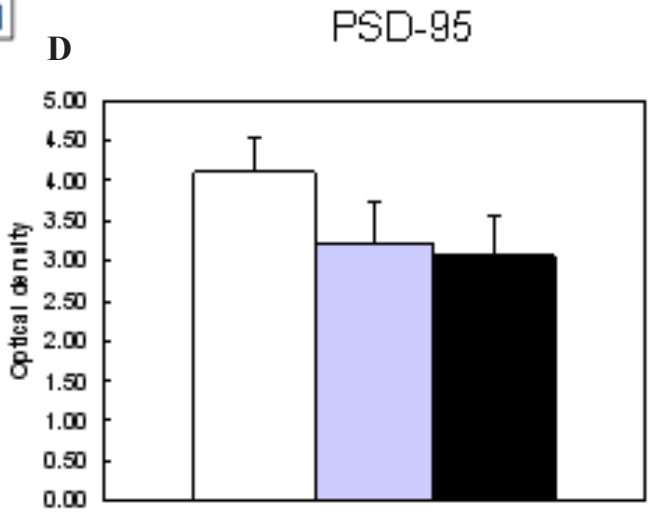

Figure 5. Effects of chronic haloperidol on synaptic protein levels assessed in whole-cell immunoblots. Each bar represents the mean $\mathrm{OD} \pm \mathrm{SEM}$ of 8-9 animals in each group. No statistically significant differences were observed for any of the proteins. 


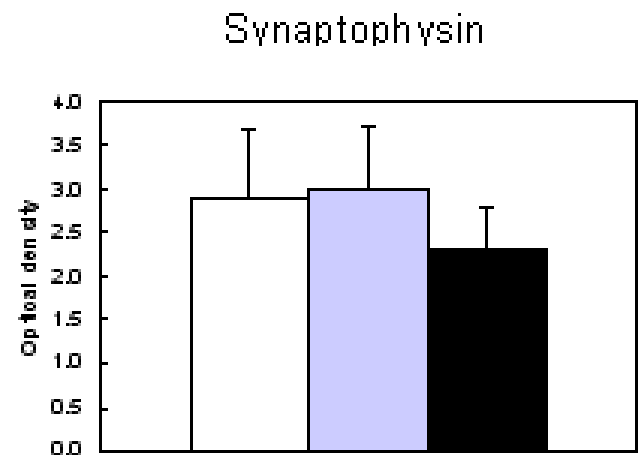

Spinophilin

C

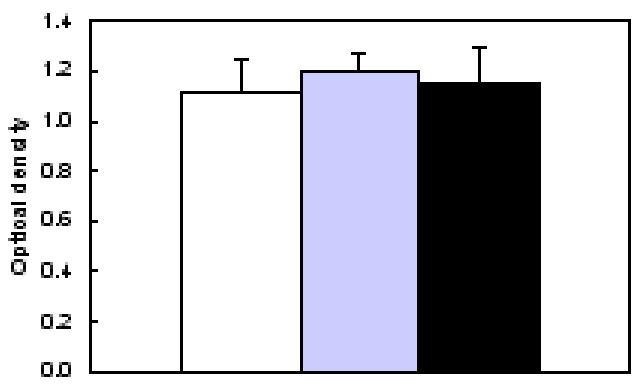

B
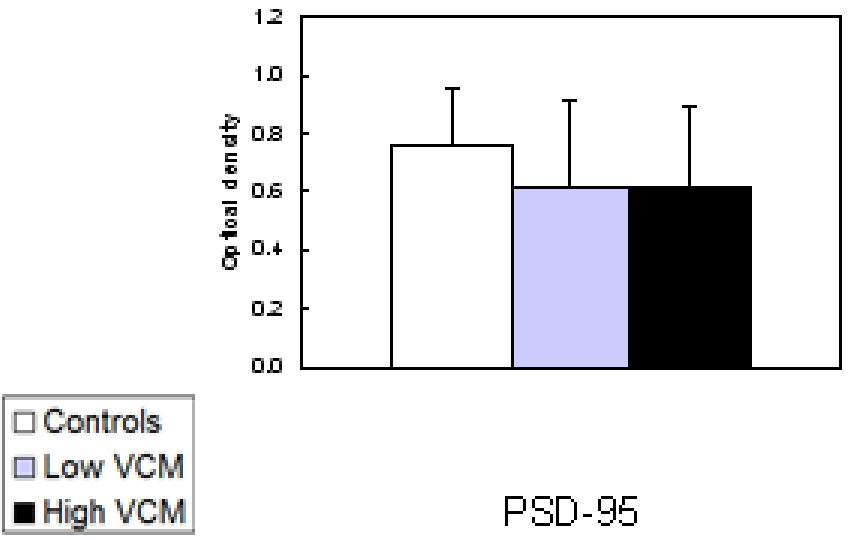

D

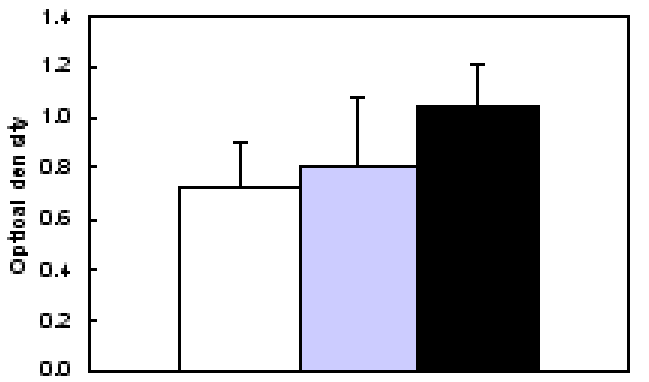

Figure 6. Effects of chronic haloperidol on synaptic protein levels assessed in synaptosomes. Each bar is the mean ( \pm sem) of 8-9 animals per group, each measured individually, except for spinophilin, where tissues from 8-9 animals per group were pooled prior to biochemical determinations. Spinophilin error bars represent variation in 8-10 aliquots from pooled tissues. No statistically significant differences were observed for any of the proteins.

\section{Discussion}

Chronic HAL treatment induced VCMs in all treated rats, which persisted for the duration of behavioural testing and showed the characteristic difference in severity between High and Low VCM subgroups, as in previous work (Egan et al., 1994; Sasaki, Kennedy, \& Nobrega, 1996; Sasaki et al., 1997). Immunohistochemical analyses and immunoblotting using either whole cell fractions or synaptosomes revealed no statistically significant difference in levels of the four target synaptic proteins between HAL-treated animals and control groups. Moreover, no differences between High and Low VCM groups were found with any of the four synaptic markers, and no differences were observed between either of the two VCM groups and vehicle-treated controls. Together these results suggest that HAL-induced VCMs are not reflected in alterations in levels of the target synaptic proteins. These results complement data from previous studies and further suggest that chronic HAL treatment may not induce significant increases or decreases in synaptic number.

\section{Previous morphological studies}

Using electron microscopy (EM) Benes and colleagues al detected a small increase in neuronal size, which they interpreted as reflecting synaptic plasticity (Benes et al., 1985a, 1985b). However, these authors administered HAL at very high does -- considerably more than used in the clinic and three times the dose used in the present study -- and it is conceivable the changes observed in that study may occur only at very high doses. Ihara and colleagues reported a decrease in the number of dopaminergic boutons and in the number of granular vesicles in the striatum (Ihara, Sato, Otsuki, Kaiya, \& Namba, 1986). However, they mention that this effect was also seen in control animals, suggesting that it may have been an age-induced rather than a drug-induced effect.

Other EM studies have detected no significant changes in morphology of synapses using EM. Ihara et al. (1986) reported that the density of granular synaptic vesicles in DA boutons did not change significantly following chronic HAL (Ihara et al. 1986). Following two weeks of HAL treatment Meshul and Casey (1989) found an increase in the number of synapses containing perforated postsynaptic densities in the caudate nucleus but not in the nucleus accumbens. The changes in the caudate were reversed after drug discontinuation drug (Meshul \& Casey, 1989). Since in the present study no changes were detected in the levels of synaptic 
markers, it is possible that changes that occur in the ultrastructure of synapses reflect re-connections rather formation of new synapses.

Other studies have compared High and Low VCM rats as far as neuronal spine size and density. In the mammalian striatum the most prevalent neuronal subtype is the medium spiny projection neuron and the majority of striatal synapses are formed with these spines (Chung, Hassler, \& Wagner, 1977; Hassler, Chung, Rinne, \& Wagner, 1978; Kemp \& Powell, 1971a, 1971b; Roberts, Gaither, Peretti, Lapidus, \& Chute, 1996). Thus, changes in spine size or density could have profound effects on striatal synaptic organization. Kelly et al. (1997) reported a decrease in spine density in HAL-treated versus control rats but no difference between High and Low VCM groups after 6 months of treatment (Kelly et al., 1997). These authors concluded that observed change in density was not related to oral dyskinesias.

Roberts, Gaither, Gao, Kashyap, and Tamminga (1995) reported a decrease in asymmetric axospinous synapses in HAL-treated animals (both High VCM and Low VCM) when compared to controls. They also detected morphological differences between High VCM and Low VCM animals. An increase was observed in mitochondrial profiles in High VCM brains accompanied by a decrease in the number of mitochondria. In addition, they reported a significant decrease in the density of symmetric axodendritic synapses in High VCM when compared to Low VCM animals. The authors suggested that this type of synapse, which is inhibitory, is key to understanding HAL-induced oral dyskinesias. Interestingly, at least two of the synaptic markers analyzed in the present study appear to localize strictly to the asymmetric type of synapses. Thus PSD-95 levels in asymmetric axospinous synapses were found to be 2-3 fold higher than levels found in adjacent cytoplasm of spines and terminals, whereas symmetric synapses were reported to show no association with PSD-95 (Aoki et al., 2001). Similarly, immunohistochemical studies revealed that syntaxin is primarily localized to pre-terminal axons and terminal varicosities that make almost exclusively type I or asymmetric synapses on dendritic spines or distal shafts (Sesack \& Snyder, 1995). Therefore, our present findings are consistent with those of Roberts et al. (1995) since our results indicate no differences in levels of synaptic proteins between High and Low VCM animals. Moreover, since these proteins are not localized in symmetric synapses, which were found to be less dense in High VCM animals, it is not surprising that no change in the levels of these markers were detected in the present study. Since this type of synapse in inhibitory, it is possible that VCMs, and similarly TD, are induced by a loss of inhibitory neurotransmission within the striatum.

Collaterals of striatal projection neurons and/or dopaminergic nigrostriatal afferents all form symmetric synapses and are thus likely to be affected in dyskinesias
(Roberts et al., 1995). Grimm et al. (2001) showed a decrease in the number of cholinergic interneurons in rats administered haloperidol for six months. More recently, Kelley et al. (2004) investigated a possible link between striatal cholinergic interneurons and oral dyskinesias in experimental animals (Kelley \& Roberts, 2004). This group reported a $22 \%$ decrease in neuronal density measures of choline acetyltransferase-labeled neurons in HAL-treated versus controls rats and a $37 \%$ reduction in the lateral portion of the striatum only in rats showing VCMs (Kelley \& Roberts, 2004). Taken together the results of these studies suggest that it would be important to conduct additional biochemical and morphological analyses to ascertain whether this decrease in striatal cholinergic interneurons precedes and causes VCMs and possibly TD or is secondary to more crucial structural changes causes by the typical APDs.

\section{Previous biochemical studies}

Attempts have been made to detect changes in synaptic and neuronal plasticity-associated genes. Eastwood and colleagues reported that chronic HAL upregulated synaptophysin mRNA but did not alter synaptophysin protein levels (Eastwood, Burnet, \& Harrison, 1994; Eastwood, Heffernan, \& Harrison, 1997). Marin and Tolosa (1997) detected an $88 \%$ increase in synaptophysin protein expression in chronically HAL-treated animals as compared to controls. However, the latter study used daily HAL injections and it is possible that route of administration affected the outcome. Both the present study and the study by Eastwood et al. (1997) involved depot administration of haloperidol once every three weeks, which allows for continuous and stable drug levels without the acute peaks and troughs in drug plasma levels associated with daily injections (Turrone et al., 2003).

There are discrepancies between results obtained with mRNA profiling and data from protein expression studies. Lidow et al. (2001) found no change in levels of synaptophysin protein in any of several cortical regions after chronic HAL, but did detect a decrease in spinophilin levels in all regions with the exception of the motor cortex (Lidow et al., 2001). Similarly, Nakahara et al. (1998) detected no significant changes in the levels of synaptophysin or SNAP 25 mRNA in the prefrontal cortex of HAL-treated rats. The latter results contradict those of Eastwood et al. (1994 and 1997) where both 2- and 16-week HAL treatments were found to up-regulate synaptophysin mRNA as assessed by in situ hybridization. Nakahara et al. (1998) attributed the discrepancy to the use of RT-PCR and a possible loss of anatomical resolution upon extraction of total mRNA from the striatum. However, while Eastwood et al. (1997) found an increase in synaptophysin mRNA, they reported no statistically significant change in the levels of synaptophysin protein following 16 weeks of HAL treatment. These results have led to 
the suggestion that chronic HAL may induce a shift in the position of synaptic contacts from dendritic spines to dendritic shafts, without significantly changing the density of synaptic contacts, such that no changes in levels of synaptic markers, either in protein or mRNA levels, are detected. Although this suggestion is based on data obtained from cortex and not the striatum, this rationale could well explain the negative results obtained in the current study.

\section{Conclusions}

After 14 weeks of continuous exposure to HAL rats displayed the expected oral dyskinesias. A detailed examination of four target synaptic proteins at the gross histological level, at the whole cell level and at the synaptosomal level failed to indicate any significant differences among brains of rats showing High vs. Low levels of VCS, or between brains of HAL-treated and control rats. Our present results further support the suggestion that HAL does not induce changes in synaptic number or morphology. This, however, does not eliminate plasticity as a possible mechanism of VCMs and/or TD since these markers do not reflect synaptic efficacy, only the number of synapses. For this reason, it remains important to investigate potential changes in functional markers of neuroplasticity (e.g. BDNF) that may play an important role in APD-induce orofacial dyskinesias.

\section{Acknowledgements}

The authors thank Roger Raymond and Mustansir Diwan for excellent technical support. Supported in part by funds from the Ontario Mental Health Foundation (Toronto, Canada).

\section{References}

Abilio, V. C., Silva, R. H., Carvalho, R. C., Grassl, C., Calzavara, M. B., Registro, S., ... Frussa-Filho, R. (2004). Important role of striatal catalase in aging- and reserpine-induced oral dyskinesia. Neuropharmacology, 47, 263-272.

Andreassen, O. A., Meshul, C. K., Moore, C., \& Jorgensen, H. A. (2001). Oral dyskinesias and morphological changes in rat striatum during long-term haloperidol administration. Psychopharmacology (Berl), 157, 11-19.

Aoki, C., Miko, I., Oviedo, H., Mikeladze-Dvali, T., Alexandre, L., Sweeney, N., \& Bredt, S.D. (2001). Electron microscopic immunocytochemical detection of PSD-95, PSD-93, SAP-102, and SAP-97 at postsynaptic, presynaptic, and nonsynaptic sites of adult and neonatal rat visual cortex. Synapse, 40, 239-257.

Benes, F. M., Paskevich, P. A., Davidson, J., \& Domesick, V. B. (1985a). The effects of haloperidol on synaptic patterns in the rat striatum. Brain Research, 329(1-2), 265-273.

Benes, F. M., Paskevich, P. A., Davidson, J., \& Domesick, V. B. (1985b). Synaptic rearrangements in medial prefrontal cortex of haloperidol-treated rats. Brain Research, 348(1), 15-20.

Calakos, N., Bennett, M. K., Peterson, K. E., \& Scheller, R. H. (1994). Protein-protein interactions contributing to the specificity of intracellular vesicular trafficking. Science, 263, 1146-1149.

Calakos, N., \& Scheller, R. H. (1994). Vesicle-associated membrane protein and synaptophysin are associated on the synaptic vesicle. Journal of Biological Chemistry, 269, 24534-24537.

Calakos, N., \& Scheller, R. H. (1996). Synaptic vesicle biogenesis, docking, and fusion: a molecular description. Physiology Review, $76(1), 1-29$.

Chung, J. W., Hassler, R., \& Wagner, A. (1977). Degeneration of two of nine types of synapses in the putamen after center median coagulation in the cat. Experimental Brain Research, 28, 345-361.

Correll, C. U., \& Schenk, E. M. (2008). Tardive dyskinesia and new antipsychotics. Current Opinion in Psychiatry, 21, 151-156.

Eastwood, S. L., Burnet, P. W., \& Harrison, P. J. (1994). Striatal synaptophysin expression and haloperidol-induced synaptic plasticity. Neuroreport, 5, 677-680.

Eastwood, S. L., Heffernan, J., \& Harrison, P. J. (1997). Chronic haloperidol treatment differentially affects the expression of synaptic and neuronal plasticity-associated genes. Molecular Psychiatry, 2, 322-329.

Egan, M. F., Hurd, Y., Hyde, T. M., Weinberger, D. R., Wyatt, R. J., \& Kleinman, J. E. (1994). Alterations in mRNA levels of D2 receptors and neuropeptides in striatonigral and striatopallidal neurons of rats with neuroleptic-induced dyskinesias. Synapse, 18, 178-189.

El-Husseini, A. E., Schnell, E., Chetkovich, D. M., Nicoll, R. A., \& Bredt, D. S. (2000). PSD-95 involvement in maturation of excitatory synapses. Science, 290, 1364-1368.

Fachinetto, R., Villarinho, J. G., Wagner, C., Pereira, R. P., Avila, D. S., Burger, M. E., ...Ferreira, J. (2007). Valeriana officinalis does not alter the orofacial dyskinesia induced by haloperidol in rats: role of dopamine transporter. Progress in Neuropsychopharmacology and Biological Psychiatry, 31, 1478-1486.

Feng, J., Yan, Z., Ferreira, A., Tomizawa, K., Liauw, J. A., Zhuo, M.,... Greengard, P. (2000). Spinophilin regulates the formation and function of dendritic spines. PNAS US A, 97, 9287-9292.

Fisher, H., \& Braun, J. E. (2000). Modulation of the SNARE core complex by dopamine. Canadian Journal of Physiology and Pharmacology, 78, 856-859.

Glazer, W. M., Morgenstern, H., \& Doucette, J. T. (1993). Predicting the long-term risk of tardive dyskinesia in outpatients maintained on neuroleptic medications. Journal of Clinical Psychiatry, 54, 133-139.

Glazer, W. M., Morgenstern, H., Schooler, N., Berkman, C. S., \& Moore, D. C. (1990). Predictors of improvement in tardive dyskinesia following discontinuation of neuroleptic medication. The British Journal of Psychiatry, 157, 585-592.

Gunne, L. M., \& Growdon, J. H. (1982). A model for oral dyskinesia in rats. Journal of Clinical Psychopharmacology, 2, 308-311.

Haddad, P. M., \& Sharma, S. G. (2007). Adverse effects of atypical antipsychotics: differential risk and clinical implications. CNS Drugs, 21, 911-936.

Halpain, S., Hipolito, A., \& Saffer, L. (1998). Regulation of F-actin stability in dendritic spines by glutamate receptors and calcineurin. Journal of Neuroscience, 18, 9835-9844.

Hassler, R., Chung, J. W., Rinne, U., \& Wagner, A. (1978). Selective degeneration of two out of the nine types of synapses in cat caudate nucleus after cortical lesions. Experimental Brain Research, 31(1), 67-80.

Ihara, Y., Sato, M., Otsuki, S., Kaiya, H., \& Namba, M. (1986). Morphological changes in rat striatal boutons after chronic methamphetamine and haloperidol treatment. Neuroscience Research, 3, 403-410.

Kelley, J. J., \& Roberts, R. C. (2004). Effects of haloperidol on cholinergic striatal interneurons: relationship to oral dyskinesias. Jorunal of Neural Transmission, 111, 1075-1091.

Kelly, M. A., Rubinstein, M., Asa, S. L., Zhang, G., Saez, C., Bunzow, J. R.,...Low, M.J.(1997). Pituitary lactotroph hyperplasia and chronic hyperprolactinemia in dopamine D2 receptor-deficient mice. Neuron, 19(1), 103-113.

Kemp, J. M., \& Powell, T. P. (1971a). The connexions of the striatum and globus pallidus: synthesis and speculation. Philos Trans $R$ Soc Lond B Biol Sci, 262, 441-457.

Kemp, J. M., \& Powell, T. P. (1971b). The site of termination of afferent fibres in the caudate nucleus. Philos Trans $R$ Soc Lond $B$ Biol Sci, 262, 413-427.

Kennedy, M. B. (1997). The postsynaptic density at glutamatergic synapses. Trends in Neurosciences, 20, 264-268.

Kennedy, M. B. (1998). Signal transduction molecules at the glutamatergic postsynaptic membrane. Brain Research Reviews, 26(2-3), 243-257. 
Kerns, J. M., Sierens, D. K., Kao, L. C., Klawans, H. L., \& Carvey, P. M. (1992). Synaptic plasticity in the rat striatum following chronic haloperidol treatment. Clinical Neuropharmacology, 15, 488-500.

Konradi, C., \& Heckers, S. (2001). Antipsychotic drugs and neuroplasticity: insights into the treatment and neurobiology of schizophrenia. Biological Psychiatry, 50, 729-742.

Li, C., Brake, W. G., Romeo, R. D., Dunlop, J. C., Gordon, M., Buzescu, R.,... McEwen, C.S. (2004). Estrogen alters hippocampal dendritic spine shape and enhances synaptic protein immunoreactivity and spatial memory in female mice. PNAS US A, 101, 2185-2190.

Lidow, M. S., Song, Z. M., Castner, S. A., Allen, P. B., Greengard, P., \& Goldman-Rakic, P. S. (2001). Antipsychotic treatment induces alterations in dendrite- and spine-associated proteins in dopamine-rich areas of the primate cerebral cortex. Biological Psychiatry, 49, 1-12.

Marin, C., \& Tolosa, E. (1997). Striatal synaptophysin levels are not indicative of dopaminergic supersensitivity. Neuropharmacology, 36, 1115-1117.

Marsalek, M. (2000). Tardive drug-induced extrapyramidal syndromes. Pharmacopsychiatry, 33 (Suppl 1), 14-33.

Matus, A. (2000). Actin-based plasticity in dendritic spines. Science, 290, 754-758.

McGlashan, T. H., \& Hoffman, R. E. (2000). Schizophrenia as a disorder of developmentally reduced synaptic connectivity. Archives of General Psychiatry, 57, 637-648.

Meshul, C. K., \& Casey, D. E. (1989). Regional, reversible ultrastructural changes in rat brain with chronic neuroleptic treatment. Brain Research, 489, 338-346.

Nakahara, T., Nakamura, K., Tsutsumi, T., Hashimoto, K., Hondo, H., Hisatomi, S.,...Uchimura, H. (1998). Effect of chronic haloperidol treatment on synaptic protein mRNAs in the rat brain. Brain Research Mol Brain Res, 61(1-2), 238-242.

Remington, G. (2007). Tardive dyskinesia: eliminated, forgotten, or overshadowed? Current Opinion in Psychiatry, 20, 131-137.

Roberts, R. C., Gaither, L. A., Gao, X. M., Kashyap, S. M., \& Tamminga, C. A. (1995). Ultrastructural correlates of haloperidolinduced oral dyskinesias in rat striatum. Synapse, 20, 234-243.

Roberts, R. C., Gaither, L. A., Peretti, F. J., Lapidus, B., \& Chute, D. J. (1996). Synaptic organization of the human striatum: a postmortem ultrastructural study. The Journal of Comparative Neurology, 374, 523-534.

Sasaki, T., Kennedy, J. L., \& Nobrega, J. N. (1996). Autoradiographic mapping of mu opioid receptor changes in rat brain after long-term haloperidol treatment: relationship to the development of vacuous chewing movements. Psychopharmacology (Berl), 128(1), 97-104.

Sasaki, T., Kennedy, J. L., \& Nobrega, J. N. (1997). Localized changes in GABA receptor-gated chloride channel in rat brain after long-term haloperidol: relation to vacuous chewing movements. Synapse, 25(1), 73-79.

Sasaki, T., Kennedy, J. L., \& Nobrega, J. N. (1998). Regional brain changes in [3H]SCH 23390 binding to dopamine D1, receptors after long-term haloperidol treatment: lack of correspondence with the development of vacuous chewing movements. Behavioural Brain Research, 90, 125-132.

Seeman, P. (2010). Dopamine D2 receptors as treatment targets in schizophrenia. Clin Schizophr Relat Psychoses, 4(1), 56-73.

Sesack, S. R., \& Snyder, C. L. (1995). Cellular and subcellular localization of syntaxin-like immunoreactivity in the rat striatum and cortex. Neuroscience, 67, 993-1007.

Soares, K. V., \& McGrath, J. J. (1999). The treatment of tardive dyskinesia--a systematic review and meta-analysis. Schizophrenia Research, 39(1), 1-16; discussion 17-18.

Sudhof, T. C. (1995). The synaptic vesicle cycle: a cascade of proteinprotein interactions. Nature, 375, 645-653.

Tamminga, C. A., Dale, J. M., Goodman, L., Kaneda, H., \& Kaneda, N. (1990). Neuroleptic-induced vacuous chewing movements as an animal model of tardive dyskinesia: a study in three rat strains. Psychopharmacology (Berl), 102, 474-478.

Turrone, P., Remington, G., Kapur, S., \& Nobrega, J. N. (2003). Differential effects of within-day continuous vs. transient dopamine D2 receptor occupancy in the development of vacuous chewing movements (VCMs) in rats. Neuropsychopharmacology, 28, 1433-1439.

Uranova, N. A., Orlovskaya, D. D., Apel, K., Klintsova, A. J., Haselhorst, U., \& Schenk, H. (1991). Morphometric study of synaptic patterns in the rat caudate nucleus and hippocampus under haloperidol treatment. Synapse, 7, 253-259.

Waddington, J. L., Cross, A. J., Gamble, S. J., \& Bourne, R. C. (1983). Spontaneous oraofacial dyskinesia and dopaminergic function in rats after 6 months of neuroleptic treatment. Science, 220, 530-532.

Yan, Z., Hsieh-Wilson, L., Feng, J., Tomizawa, K., Allen, P. B., Fienberg, A. A.,... Greengard,P. (1999). Protein phosphatase 1 modulation of neostriatal AMPA channels: regulation by DARPP32 and spinophilin. Nature Neuroscience, 2(1), 13-17. 